\title{
Relationship and role transformations in social media environments
}

Hazel Hall, Professor and Director, Centre for Social Informatics, Edinburgh Napier University, Edinburgh EH10 5DT, UK

h.hall@napier.ac.uk

$+44(0) 1314552760$

This is the manuscript of the paper published in volume 29 issue 4 of The

Electronic Library.

\section{Biographical note}

Dr Hazel Hall is Professor and Director of the Centre for Social Informatics at Edinburgh University, Edinburgh, UK. Since 2009 she has also been seconded two days a week to lead the implementation of the UK Library and Information Science Research Coalition.

For further details at: http://www.soc.napier.ac.uk/ hazelh/esis/hazel.html

\begin{abstract}
Purpose

To challenge how librarians conceive a number relationships - between themselves, social media tools, and end-users, and to argue that this determines the boundaries of service innovation.
\end{abstract}

\section{Design/methodology/approach}

Develops themes and ideas derived from research projects on deployment of social media by library and information professionals completed within the Centre for Social Informatics at Edinburgh Napier University. (The article is based on a keynote presentation delivered at Internet Librarian 2010 (Hall, 2010).)

\section{Findings}

Librarians currently demonstrate more sophisticated use of social media for personal professional purposes than they do for services delivery; a number of challenges currently limit the extent to which librarians are able to exploit social media to full advantage; fuller exploitation of social media is possible when (1) librarians transfer the good practice exhibited in personal professional use of to applications for services delivery, (2) service innovations are considered before tools, and (3) end users are treated as collaborating clients rather than consuming customers.

\section{Originality/value}

Of interest to those keen to take advantage of the opportunities offered by social media that extend beyond replicating existing service delivery. 
Relationship and role transformations in social media environments

\section{Keywords}

Social media, innovation, end-users, collaboration, services delivery

\section{Paper classification}

Viewpoint 


\section{Introduction}

Based on a keynote paper presented at Internet Librarian International 2010 (Hall, 2010), this article argues that the way in which librarians conceive a number of relationships - between themselves, social media tools, and end-users - determines the boundaries of service innovation. The discussion is set against a context that considers how social media currently provide additional platforms for traditional information services delivery, the characteristics that social media share with other technological implementations, and the corresponding challenges that these present. It is argued that the sophisticated deployment of social media exhibited by librarians in their personal professional use of tools is yet to be extended into mainstream services to end-users. Moreover, the potential of social media as a platform for collaborative working where endusers and librarians develop services together remains to be exploited. This work draws on recent research on collaboration in online environments completed at Edinburgh Napier University. The perspective is that of a researcher with a background in information services provision, who is also a regular consumer of information delivered over social media platforms. The social media implementation at the UK Library and Information Science Research Coalition (http://lisresearch.org) is deployed to illustrate points made in the discussion.

\section{Levels of social media sophistication amongst librarians for personal professional purposes and services delivery}

Social media offer a number of applications that are relevant to many types of organisation, including libraries. For example, much public relations and marketing effort is now spent on developing content for Facebook, Twitter and organisation-branded blogs. In terms of specific library and information services functions, social media provide useful additional platforms. For example:

- Information discovery and access is facilitated through the use of social book-marking and blogging, for example in the provision of alternative means for the presentation of subject guides.

- Reference services extend beyond the physical enquiry desk when instant messaging and chat are offered as additional channels through which to access specialist staff.

- Teaching and related activities can benefit greatly through the inclusion of YouTube videos and podcasts in classes and training sessions.

- News and current awareness services have a greater immediacy and reach when relayed by library Twitter accounts and blogs.

However, in cases where social media are conceived by librarians solely as substitute information delivery channels, they are often under-exploited. For instance, using a library Twitter account to broadcast information to a follower population of users without following back is simply "twinforming". Genuine tweeting would comprise following back in order to form more extensive relationships with follower community members. Similarly, it might be argued 
that using a platform such as WordPress solely to display library opening hours, or details of forthcoming events, on largely static pages where comments are disabled does not really represent blogging. Lacking here is an appreciation that there is more to the implementation of social media tools in the library setting than the replication of existing services for an audience of information consumers.

This not to say that librarians lack sophistication in their use of social media in the workplace. Indeed a large number have highly-developed strategies for integrating social media tools into their personal professional lives. They deploy these tools to advantage in the support of participative and collaborative work within their peer groups:

- For project work and learning they communicate via wikis, blogs, instant messaging, and organise online tweet-ups.

- For staff development at a distance they participate in amplified events and engage in new forms of professional networking.

- For personal profile-raising (intentional or accidental) they tweet and blog from personal accounts.

- For efficiency at work they free themselves from the shackles of online discussion lists in favour of strategic Twitter following.

- For improving professional publication efforts they peer review ideas and work from Twitter and blogs.

- For testing out ideas for services developments they harness the network to crowd-source ideas, for example by putting out queries and suggestions, and answering them, in the blogosphere and over Twitter.

A number are also quick to experiment as soon as new tools become available. Their minds are open to the possible library applications of tools primarily designed for other purposes. For example, they might consider the release of a new location-based social networking application as a possible means of devising induction games for an academic library setting, or to set up a reward scheme for regular public library visitors. Equally, they take apparently simple tools and deploy them in imaginative ways. For example, tag clouds make interesting visual representations on publicity material, or provide a quick means of assessing written feedback on events. These librarians are also often those who have explored the advanced features of the more commonly-known tools and use them to their full advantage.

However, such levels of sophistication of use of these new tools are less evident in the implementation of social media for services delivery to end-users. Even less evident are joint staff-user services developments. For example, in a recent study of the deployment of Twitter amongst librarians a strong conclusion was that they are more likely to take fuller advantage of the tool for personal professional use, for example for their own training and development purposes, than for direct services delivery to end-users (Loudon \& Hall, 2010). Services enhancements may thus derive from librarians' personal social media use. This is because librarians identify professional reading, find out about events to attend, 
follow events that they cannot attend in person, and maintain links with peers and mentors through Twitter. These activities all contribute to librarians' professional development which, it would be expected, feeds into their daily work practice. However, less prevalent are examples of instances where librarians and users work collaboratively with these tools to develop service innovations together.

The social media implementation at the Library and Information Science (LIS) Research Coalition illustrates the limitations cited above. Here a small professional organisation has harnessed social media to extend practices longestablished elsewhere. Aimed at an end-user population of librarians and information scientists, the LIS Research Coalition's media coverage page (hosted on a blog at http://lisresearch.org), for instance, provides an ordered archive of news stories of relevance to its work. Similarly the Coalition's Twitter feed (@LISResearch) relays valuable information about library and information science research matters to its followers.

The nature of the LIS Research Coalition's deployment of social media is echoed across a number of library contexts, where librarians push out information to their end-user communities. These services are useful and valued, but hardly innovative. For example, the Coalition's media coverage page is simply a more readily accessible press cuttings file, and the output from the Twitter account is instantly recognisable as a traditional current awareness service, albeit in a slightly different, online and more frequently updated, guise. Indeed the resources offered by the LIS Research Coalition to date have barely evolved as a result of collaboration between the Coalition and its end-user audience, even though it is heavily dependent on tools that are celebrated for their support of participative endeavours. Recognition that the LIS Research Coalition's social media implementation shares characteristics of those of mainstream library and information services raises the question as to the extent to which librarians are exploiting the full potential of social media in services delivery. Are they genuinely engaging with their stakeholder communities in a participatory, collaborative fashion to take full advantage of social media tools? With the exception of library campaigning ${ }^{1}$, supported by the publishing industry amongst others, and which is less about services delivery and more about services advocacy and survival, the answer is probably not.

\section{Challenges to full exploitation of social media in library environments}

The reasons why social media tools are currently under-exploited by librarians in terms of services delivery are various. Some of the challenges faced by those keen to take advantage of the new tools are novel in themselves. Others are familiar to those with an interest in sociotechnical studies. In particular, earlier studies of the introduction of new technologies in work place environments

\footnotetext{
${ }^{1}$ Such as the 2011 activity in the UK which deployed blogs (for example, http://www.voicesforthelibrary.org.uk/wordpress/), Facebook (for example, https://www.facebook.com/pages/Fight-For-Libraries-campaign-from-TheBookseller/134767896588119) and Twitter (hashtag \#savelibraries).
} 
point to how new technologies settle into organisational contexts in unexpected ways. This is often in response to the challenges faced by those charged with the implementation, as well as their reception by end-users.

A major challenge to those building new services around social media applications is the overwhelming choice of tools. Faced with a plethora of options, it is difficult to know where to start. For example, it is often not obvious which tool is most suitable to a particular application. As illustration, the LIS Research Coalition considered setting up an awards wiki accessible from http://lisresearch.org. Here those offering awards to LIS practitioners could update details of new calls for award applications as and when they became available. This would give additional publicity to the awards on offer and, it was hoped, encourage greater numbers of librarians to respond to the calls by making applications. After some experimentation the idea of a wiki was abandoned. It was concluded that providing a feed from the established LISawards JISC mailing list ${ }^{2}$ to the LIS Research Coalition web site was a simpler solution for publicising awards, and one that would not require duplication of effort. The feed now sits on the right-hand column of pages at http://lisresearch.org. Similarly, an application that makes sense as an addition to a repertoire of social media for personal purposes may not integrate well with services for end-users. Anyone who has questioned their personal identity on Twitter with relation to their follower audience - be it peers, customers and clients, social or family contacts, or a mix of all these - will recognise this issue. These examples illustrate the question of what not to do with social media may be just as important as what to do.

A means of identifying where to focus attention with regards to social media choice is for librarians to step away from their immediate library-based peers to see what works in other domains. A number of informal networking groups for those interested in social media have sprung up over the past couple of years, often as a consequence of Twitter contacts seeking out their followers for regular face-to-face meetings, or tweet-ups ${ }^{3}$. For example, in Edinburgh the Edinburgh Coffee morning ${ }^{4}$ draws together professionals from a range of backgrounds such as design, marketing, engineering and performance arts - to share hints and tips about their new social media discoveries. This group meets on Fridays at 103 George Street from 08:00am onwards. In London a social media cafe ${ }^{5}$ entitled "The Tuttle Club" also runs on Fridays from 10:00 to midday at the Centre for Creative Collaboration at 16 Acton Street. Participation at these fora can also help generate imaginative ideas for service delivery as new knowledge is generated at the boundaries of individuals' shared interests.

\footnotetext{
2 lis-awards@jiscmail.ac.uk

3 This may lead to questioning as to the extent to which social media are genuinely "social". If Twitter is a media that is social, why do people attend tweet-ups of this nature? The explanation is the same as that we use to explain why we still carve messages on stones (grave markers), craft letters in ink (thank you letters) etc: because basic human needs and behaviours are more constant that the distracting "movement" created by new technology.

${ }^{4}$ http://38minutes.ning.com/group/edinburghcoffeemorning

${ }^{5}$ See http://tuttleclub.wordpress.com/
} 
A further challenge for librarians is to convince all stakeholders that engagement with social media is no longer an option for information services delivery. The problem of buy-in has been recognised within the community for a number of years, as shown in the results of an Edinburgh Napier-TFPL study conducted amongst a range of information professionals in 2008 on the risks and opportunities offered by social media (Hall, Golzari, Blaswick \& Goody, 2008). This project analysed views on the relative value of individual social media applications at the time that organisations were beginning to consider their serious use in the workplace. The findings of the study revealed that the greatest risks associated with social media applications related to their integration within organisations, with partial or non-adoption raising the most fears. This risk was prioritised over all others. It was regarded as more important than risks to the smooth running and maintenance of information management processes, security, productivity and online citizenship.

Since the publication of the Edinburgh Napier-TFPL study three years ago awareness of social media, and their integration into daily life, has grown. These tools "are not an alternative to real life, they are part of it" (Shirky, 2010, p. 37). In short, social media now contribute to the infrastructure of our everyday activities, both at work and at home. From social media librarians (as do many others) learn a mix of professional and personal information. This ranges from, for example: important dates for forthcoming conferences to family trivia; happenings in the wider library and information science profession to the news that a friend has a new baby; details of who works where to how to locate a colleague on the train; the cost of professional subscriptions to join a group to that an alert that a friend has died. The detail of this list also demonstrates how social media applications are aggregators of individuals, of their lives, and of their experiences. They are not mere aggregators of information. This gives social media an added dimension when compared with more traditional IT tools such as databases. The established technologies serve as simple repositories of data, and lack the richness of the newer tools, such as social networking applications that reveal not only information per se, but also information about those who hold the information, and the relationships between individuals, groups and information. This richness, derived from the contextual signals that envelop the information content, is not necessarily viewed positively by all, however, and this raises a further challenge. Any association with "trivia" of everyday life reinforces the view that a tool labelled "social" is some kind of plaything 6 that necessarily relates to leisure activities. This strengthens the case for some employers to continue to refuse access from work to the very tools on which librarians may wish to build service innovations. For librarians working in certain sectors such as government, the health service and some public authorities this has been a major challenge, and another to add to the perceptions of risk associated with data security in social media environments. One workaround has been for librarians (who are often ahead of the game within their organisations in the recognition of the importance of social media), where

\footnotetext{
${ }^{6}$ This is not helped by the names of some of the tools and platforms (for example, Twitter, iPad) although with time the initial connotations associated with the labels fade.
} 
possible, to implement services on social media platforms without first seeking permission. Only afterwards do they write the policy documentation. However, this has not been an option for those working in environments where access is completely blocked 7 .

A characteristic that all newer tools share with older technologies is that they are subject to adaptation by those who adopt and use them. End-user tinkering with technology and its function surrounds us, both on a small and large scale. Take for example the device initially conceived to eradicate the need for carbon paper that now serves as a publishing machine (the photocopier); the original short messaging system that now carries long conversations (the landline telephone); and the telephone that found widespread user adoption thanks to its messaging, rather than voice, function (the mobile phone). Detailed sociotechnical studies of technology implementations demonstrate the multiple, unexpected roles of technology that are context dependent and subject to user uptake. For example, a new corporate information system developed ostensibly for knowledge sharing may also serve as the pet project of the team that kicks off the initial development work, a status symbol proudly presented at conferences beyond the home organisation, a tool to measure internal productivity, or a career ladder for those seconded to the development team. In short, tool function is in the eye of the beholder, and this changes over time. To illustrate how this concept applies to social media it is worth pointing to the cases of Wikipedia and Twitter. Wikipedia was conceived as an online encyclopaedia, and continues to be described as such, but it may equally be considered as a source of breaking news. This claim can be tested by checking the site's Current Events page at http://en.wikipedia.org/wiki/Portal:Current events. Similarly the initial label for Twitter as a "microblog" gives the impression that its function is the delivery of short status updates to subscribers. The difficulty that those who "get" Twitter face when explaining its various functions to those whose view is tarnished by journalistic "Stephen Fry stuck in a lift" stories is ample illustration of how users have discovered multiple functions for this tool. It is also interesting to note how Twitter is conceptualised by individuals over the course of their interactions in blog posts and presentations ${ }^{9}$. Uncertainty as to the ultimate application of a tool adds to the problem of knowing which to adopt and which to ignore (as noted above). A more positive analysis is that there is potential for all to be part of the processes where the adoption of new tools incorporates innovative developments, including users alongside those with official responsibility for the service. This fits with the spirit of social media interactions, and can help more librarians move away from the broadcast model in their own deployment of social media with end-users.

\footnotetext{
${ }^{7}$ If such attitudes were to be applied to e-mail, entire systems would be shut down whenever someone inadvertently replied to list.

${ }^{8}$ On $3^{\text {rd }}$ February Stephen Fry famously tweeted "OK. This is now mad. I am stuck in a left on the $26^{\text {th }}$ floor of Centre Point. Hell's teeth. We could be here for hours. Arse, poo and widdle."

${ }^{9}$ See, for example, Brian Kelly's October 2008 post at http://ukwebfocus.wordpress.com/2008/10/21/getting-twitter/ and the five stages of Twitter acceptance described in "How Twitter saved my life" at http://www.slideshare.net/minxuan/how-twitter-changed-my-life-presentation. The 46 stages of Twitter at http://www.shanenickerson.com/nickerblog/2009/06/the-46-stages-oftwitter.html provides a very amusing take on the same theme.
} 


\section{Conclusion: from librarian broadcasters and end-user consumers to social media collaborators}

It is perhaps inevitable that a professional group talented at organising and communicating information has predominately, to date, used social media as an extension to traditional practice, where librarians have played the role of broadcasters to an end-user consumer audience. The need now is to recognise that much can be achieved by conceiving social media in different ways. For example, rather taking a tool and considering how its features can be applied to existing practice ${ }^{10}$, librarians are encouraged to regard social media from the opposite direction: to question how to develop services, then identify possible social media tools for particular aspects of services delivery. Now is the time to capitalise on the recent developments in mobile computing: many end-users, particularly in academic and special library settings, permanently carry on their person devices that facilitate such participation.

This work should involve evaluating the role that end-users can play in the process of development. Here social media might facilitate end-user involvement in the actual design of a new or enhanced service, ultimately serve as the platforms for service delivery, or simply offer channels for assessing user information needs at the start of the project. Librarians' personal professional use, as well as the successful applications of social media in the recent library campaigns - many of which have included much stakeholder involvement provide evidence that such an approach is possible. A successful strategy will see librarians stewarding a process whereby key end-users transform from consumers to collaborators, generating lead communities that start to build user-generated services and offer client self-support. New services or resources created by librarians on the basis of community needs may be extended and developed by the most enthusiastic end-users who respond to the basic human instinct that encourages them make and share. Success in developing relationships and roles will harness social media for innovation in services delivery beyond the traditional broadcaster-consumer model which should closely align with matching needs of the communities to be served.

\section{References}

Hall, H. (2010), “Getting real about social media” keynote paper presented at Internet Librarian International 2011 (ILI2011), 13-15 October, London, UK, available at: http://www.dcs.napier.ac.uk/ hazelh/esis/Hall ILI.ppt (accessed 8 March 2011).

Hall, H., Golzari, S., Blaswick, B., \& Goody, M. (2008), “Opportunity and risk in social computing environments", available at:

\footnotetext{
10 This is often how reports of social media in libraries are presented in the literature and conference presentations, with the focus on technology rather than service provision.
} 
http://www.soc.napier.ac.uk/ hazelh/esis/soc comp proj rep public.pdf (accessed 8 March 2011).

Loudon, L. \& Hall, H. (2010), "From triviality to business tool: the case of Twitter in information services delivery", Business Information Review, Vol 27, no 4, pp 236-241.

Shirky, C. (2010), Cognitive Surplus: Creativity and Generosity in a Connected Age, Penguin, London. 